\title{
Metacognitive illusions for auditory information: Effects on monitoring and control
}

\author{
Matthew G. Rhodes \\ Colorado State University, Fort Collins, Colorado \\ AND \\ Alan D. Castel \\ University of California, Los Angeles, California
}

\begin{abstract}
Prior work has demonstrated that the perceptual features of visually presented stimuli can have a strong influence on predictions of memory performance, even when those features are unrelated to recall (Rhodes \& Castel, 2008). The present study examined whether this finding would hold in an auditory domain and influence study-choice allocation. Participants listened to words that varied in volume, made judgments of learning (JOLs) for each item, and were then administered a test of free recall. In Experiment 1, we showed that JOLs were influenced by volume, with loud words given higher JOLs than quiet words, and that volume had no influence on recall, illustrating a metacognitive illusion based on auditory information. In Experiment 2, we extended these findings to control processes and showed that participants were more likely to choose to restudy quiet words than loud words. These findings indicate that highly accessible auditory information is integrated into JOLs and restudy choices, even when this information does not influence actual memory performance.
\end{abstract}

A great deal of research has examined the manner in which participants make predictions of memory performance (for reviews, see Koriat, 2007; Metcalfe, 2000). The most common research method has been to solicit judgments of learning (JOLs) either immediately after the presentation of an item or following a delay. JOLs are often accurate, but a number of important discrepancies have been observed between actual and predicted memory performance (see, e.g., Begg, Duft, Lalonde, Melnick, \& Sanvito, 1989; Benjamin, Bjork, \& Schwartz, 1998; Castel, McCabe, \& Roediger, 2007; Koriat \& Bjork, 2005; Mazzoni \& Nelson, 1995; Rhodes \& Castel, 2008). Such discrepancies provide some indication of the bases for JOLs. For example, Benjamin et al. recorded participants' latency for answering general knowledge questions. Immediately after providing an answer, participants predicted the likelihood that they would later remember that answer when given the opportunity for recall. The results showed that the answers that were retrieved most quickly were given the highest JOLs. However, the opposite pattern was apparent for recall; it was the items with the longest latencies that were most likely to be recalled (but see Koriat, 2008). Such data suggest that JOLs were based on the ease with which answers were retrieved, rather than on other, more diagnostic bases for predicting recall.

The present study is likewise concerned with cases in which participants base JOLs on cues that are not diagnostic of subsequent memory performance. In particular, we focused on a class of cues that have not been thoroughly examined in previous research - namely, manipulations of the perceptual qualities of to-be-remembered stimuli. Several lines of work suggest that the perceptual properties of information, such as its clarity, can have a strong influence on memory (for reviews, see Jacoby, Kelley, \& Dywan, 1989; Kelley \& Rhodes, 2002; Schwarz, 2004). For example, perceptually clear stimuli (see, e.g., Busey, Tunnicliff, Loftus, \& Loftus, 2000; Whittlesea, Jacoby, \& Girard, 1990) are more likely to be regarded as having been previously studied than are stimuli that have been perceptually degraded. In addition, manipulations that enhance the ease with which an item is identified or processed often increase the probability that the item will be judged as having been previously encountered (see, e.g., Jacoby \& Dallas, 1981; Rhodes \& Kelley, 2003).

Very few studies have examined whether JOLs are likewise influenced by variations in perceptual information (Busey et al., 2000; Rhodes \& Castel, 2008; see also Korenman \& Peynircioğlu, 2004). Busey et al. had participants study faces at different levels of luminance, so that the faces were studied in high to low levels of contrast. Following the presentation of each face, the participants predicted whether they would be able to recognize the face on a later test. The results showed that predictions and recognition performance were influenced by luminance. More recently, however, Rhodes and Castel reported data suggesting that perceptual information in the visual do-

M. G. Rhodes, matthew.rhodes@colostate.edu 
main influences predictions, even when such information is unrelated to memory performance. In particular, participants studied and made JOLs for words, half of which were presented in a large (48-pt) font, and half of which were presented in a small (18-pt) font. Across several experiments, participants consistently regarded large words as being more memorable than small words, even though recall did not differ between the two conditions. Rhodes and Castel concluded that participants integrate easily available perceptual information (font size) when making JOLs, even when that information is not diagnostic of future memory performance.

Nevertheless, several questions linger regarding the influence of perceptual information on memory predictions. For example, each of the experiments used a visual presentation of a word, and, perhaps, visual information is easily integrated when making JOLs. A similar pattern of findings in a different modality would make a stronger case, that, more generally, perceptual information informs JOLs, even when this information is not diagnostic of later recall. We examined this in the present study by presenting items for study in an auditory modality. Specifically, in each experiment, participants listened to words presented at a quiet (conversational) volume and to words that had been adjusted to be presented at a substantially louder volume. If participants regard words of greater perceptual intensity as being more memorable than words of a lesser intensity, then JOLs should be higher for words presented at the louder volume. If prior findings do not generalize to an auditory domain, one would expect there to be little or no relation between JOLs and the volume at which words are presented for study.

In addition to extending these principles to an auditory domain, the present study also focused on an issue of key theoretical interest. Specifically, given that prior work examining the influence of perceptual cues on metacognition has focused entirely on monitoring, it is unclear whether perceptual information influences control processes involved in the regulation of study. This is particularly important, as many frameworks suggest that monitoring plays a causal role in the control processes related to self-guided learning (Nelson, 1996; but see Koriat, Ma'ayan, \& Nussinson, 2006). For example, the discrepancy reduction theory states that learners seek to reduce the discrepancy between their current state of learning and their desired or optimal state of learning (Dunlosky \& Hertzog, 1998; Thiede \& Dunlosky, 1999; but see Metcalfe \& Kornell, 2005, for a different account). Consequently, learners are expected to allocate more study time to items perceived as being more difficult to learn than to easier items, for which the discrepancy between the current and desired state of learning is smaller (see, e.g., Dunlosky \& Thiede, 2004). To our knowledge, no prior studies have examined the potential influence of perceptual information on self-regulated study. This issue is critical for theories of what cues govern selfregulated study, as it is unclear whether participants will select items for restudy on the basis of perceptual characteristics. Thus, in order to determine whether control processes are influenced by the perceptual features of stimuli, we asked the participants in Experiment 2 to make restudy choices among items presented at loud and quiet volumes. If participants indeed regard quiet items as being less memorable than loud items, they should seek to restudy quiet items more frequently than loud items.

To summarize, in the present study, we investigated the extent to which perceptual information influences JOLs. In Experiment 1, participants made JOLs for words presented at quiet and loud volumes, permitting us to examine the degree to which variations in perceptual information influence JOLs. In Experiment 2, we tested whether perceptual information influences choices about which items to restudy, examining how metacognitive control is influenced by the perceptual features of stimuli.

\section{EXPERIMENT 1}

\section{Method}

Participants. Twenty Colorado State University psychology students participated for partial course credit. Each participant was tested individually.

Materials. The materials consisted of 42 nouns taken from the Kučera and Francis (1967) norms. These were randomly divided into two sets of 18 items that were presented equally often at a quiet or loud volume. The two sets were equated for word frequency $(M=$ 46.81), number of letters $(M=5.94)$, and number of syllables $(M=$ 1.86). The remaining 6 items served either as primacy or recency buffers, presented equally often as a quiet or loud item, and were excluded from all analyses reported. All items were recorded and edited using Adobe Audition Software. Items were recorded in a male voice and adjusted so that, for each item, there was a version at a quiet (conversational) volume and one at a loud volume, with the average volume for loud items increased by a factor of approximately 3 . As a manipulation check, we had 8 participants (not tested in any other portion of the experiment) listen to the stimuli and make a rating of loudness for each item, on a scale from 1 (very quiet) to 7 (very loud). The results showed that loud words (mean rating = $6.52, S E=.08)$ were indeed regarded as being far louder than quiet words (mean rating $=2.40, S E=.11)[t(7)=24.76$, Cohen's $d=$ 14.75].

Procedure. After providing informed consent, participants first listened to a series of four words (not presented at any other time in the experiment), presented one at a time through two speakers located immediately adjacent to the monitor. Volume levels were then adjusted by the experimenter to ensure that the participant could clearly identify the items presented (this did not vary substantially; all participants reported normal hearing). The participants then proceeded to the study phase and were informed that they would hear words presented at different volumes. They were instructed to rate the likelihood of later recalling that word, on a scale from 0 (not likely at all) to 100 (very likely) immediately after each word was presented. The participants were encouraged to use the entire range of the scale. Following each word, participants were given $4 \mathrm{sec}$ to record their JOL on a sheet of paper. The study items were presented in a fixed random order at a 5-sec rate, with the condition that no more than three items of the same volume were presented consecutively. Immediately following the study list, participants engaged in a filler task for approximately $5 \mathrm{~min}$, in which they were required to write the names of the states of the United States. Finally, participants were instructed to write, on a blank sheet of paper, as many of the words as they could remember from the study list on a blank sheet of paper provided. Participants were given $4 \mathrm{~min}$ for the free recall task.

\section{Results and Discussion}

Predicted and actual recall data are presented in Figure 1 . The results showed that participants regarded loud 


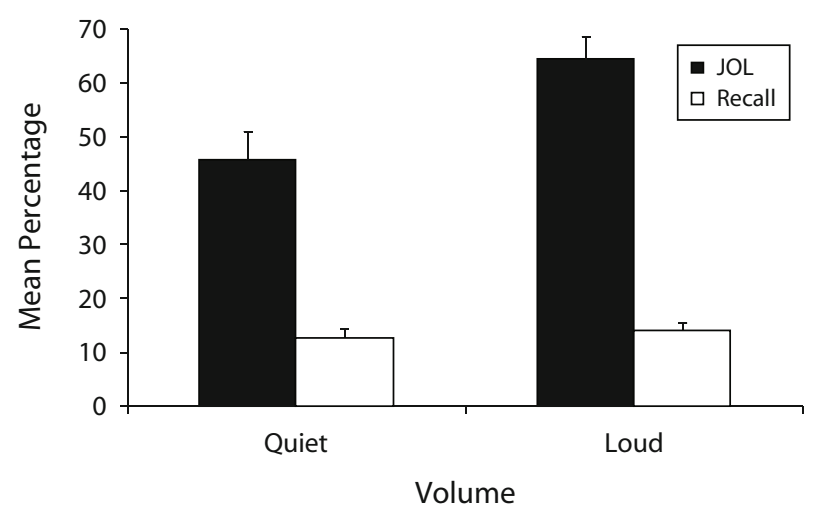

Figure 1. Predicted and actual recall performance by volume in Experiment 1. Error bars reflect standard errors of the means.

words $(M=64.33, S E=4.34)$ as being more memorable than quiet words $(M=45.81, S E=5.17)[F(1,19)=$ $\left.29.75, \eta_{\mathrm{p}}^{2}=.61\right]$. However, actual recall did not differ between loud and quiet words $(F<1)$.

We also examined the relation between volume, JOL, and recall by calculating Goodman-Kruskal gamma correlations for each participant (Nelson, 1984). If volume informs JOL, so that higher JOLs are given for loud items, a positive correlation should exist between volume and JOL. The results showed that, whereas the mean correlation between volume and JOL $(\gamma=.49, S E=.07)$ differed reliably from zero $[t(19)=6.66]$, the mean correlation between volume and recall $(\gamma=.13, S E=.12)$ did not differ from zero $[t(19)=1.06, p=.30]$.

Thus, the findings from Experiment 1 were consistent with the phenomenon previously documented by Rhodes and Castel (2008) and extend those data to an auditory domain. Specifically, whereas Rhodes and Castel's participants regarded large words as being more memorable than small words, participants in Experiment 1 regarded loud words as being more memorable than quiet words. In Experiment 2, we asked whether the perceptual features of stimuli presented for study would likewise influence control processes in metacognition.

\section{EXPERIMENT 2}

Data from Experiment 1 showed that participants regarded loud words as being more memorable than quiet words, despite no reliable difference in recall. Such data support the more general notion that participants use the perceptual intensity of stimuli as a basis for JOLs. However, it is unclear whether perceptual information guides control processes, such as the self-regulation of study. We examined this in Experiment 2 by asking participants to decide, for each item presented, whether they would like the opportunity to restudy that item. As noted previously, the discrepancy reduction theory (Dunlosky \& Hertzog, 1998; Thiede \& Dunlosky, 1999) suggests that participants choose to allocate the most study time to items they regard as having the largest discrepancy between the current learning state and the desired learning state. Thus, if perceptual information influences control processes, participants should more frequently choose to restudy quiet words; that is, because quiet words are perceived as being less well learned than loud words, they should be chosen for restudy more often. Such a finding would extend the discrepancy reduction model to cues that include the perceptual features of stimuli presented at encoding.

\section{Method \\ Participants. Twenty-six Colorado State University psychology students participated for partial course credit. Each participant was tested individually. \\ Materials and Procedure. The materials and procedure were identical to those in Experiment 1, with one exception: Immediately after studying and making a JOL for each item, the participants indi- cated (by circling yes or no on the answer sheet) whether they would like the opportunity to restudy that item at a later time. Following the filler task, participants were given a free recall test, but they were not given the opportunity to restudy.}

\section{Results}

Predicted and actual recall data are presented in Figure 2. Consistent with Experiment 1, participants regarded loud words $(M=60.25, S E=3.94)$ as being more memorable than quiet words $(M=45.68, S E=3.55)[F(1,25)=$ $\left.19.74, \eta_{\mathrm{p}}^{2}=.44\right]$. In contrast, recall did not differ between the two conditions $\left[F(1,25)=1.33, p=.26, \eta_{\mathrm{p}}^{2}=.05\right]$. Data for gamma correlations likewise showed that JOLs were strongly related to volume $(\gamma=.47, S E=.07)$ $[t(25)=7.03]$, whereas there was no reliable relationship between volume and recall $(\gamma=.09, S E=.11)(t<1)$.

Of greater importance are the data for restudy choice. The results showed that participants chose to restudy a reliably larger percentage of quiet words $(M=39.10$, $S E=6.45)$ in comparison with loud words $(M=19.87$, $S E=4.65)\left[F(1,25)=14.57, \eta_{\mathrm{p}}^{2}=.37\right]$. Consistent with this, volume was negatively related to study choice $(\gamma=$ $-0.50, S E=0.10)[t(17)=5.12]$. In addition, JOLs were negatively related to study choice $(\gamma=-0.87, S E=0.04)$ $[t(17)=22.15]$ (cf. Son \& Metcalfe, 2000).

The results from Experiment 2 thus showed that JOLs were sensitive to the volume at which items were studied. More important, Experiment 2 demonstrated that restudy

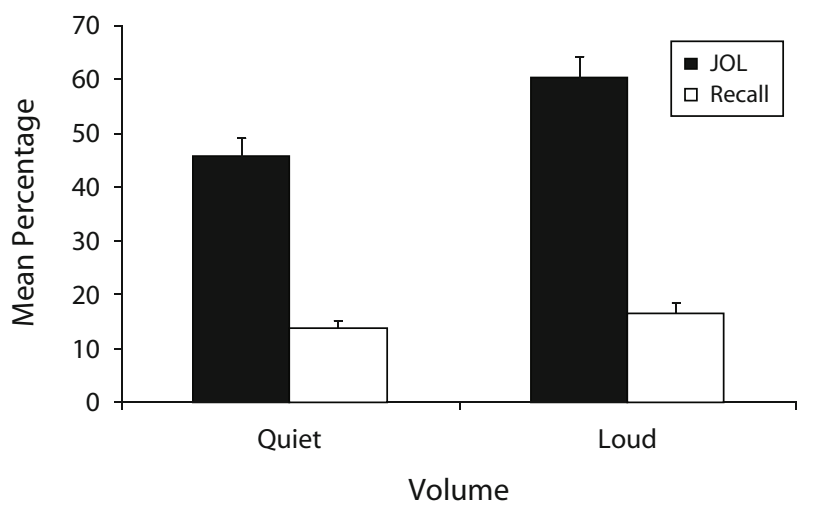

Figure 2. Predicted and actual recall performance by volume in Experiment 2. Error bars reflect standard errors of the means. 
choice was influenced by the perceptual features of stimuli, so that participants were more likely to choose to restudy quiet words. These data suggest that manipulations of the perceptual features of stimuli not only influence monitoring but also have a direct impact on control processes.

\section{GENERAL DISCUSSION}

The present study provides support for the notion that perceptual cues exert a strong influence on predictions of memory performance, even when such cues are not diagnostic of later recall. The results from Experiment 1 showed that participants regarded items presented at a loud volume as being more memorable than items presented at a quiet volume, despite the fact that there was no difference in recall. These findings parallel other data (Busey et al., 2000; Rhodes \& Castel, 2008) that suggest that participants integrate salient perceptual information when predicting future memory performance. One possibility is that presentation at a louder volume leads to greater perceived fluency, or ease of processing at encoding, which then guides JOLs (e.g., Hertzog, Dunlosky, Robinson, \& Kidder, 2003; Oppenheimer, 2008; Rhodes \& Castel, 2008).

Experiment 2 replicated the finding of higher JOLs for louder items (with no impact of volume on recall) and is the first study, to our knowledge, to document the relation between perception and metacognitive control processes, showing that participants were more likely to choose to restudy quiet items. These data are consistent with other work that shows that JOLs influence control processes in a manner that is dissociated from recall (Metcalfe \& Finn, 2008), suggesting a causal role for metacognitive judgments in restudy choice. In particular, whereas recall was unaffected by the volume at which words were presented, predictions and restudy judgments were affected by volume.

Data from Experiment 2 are also informative regarding the discrepancy reduction model of monitoring and control. The discrepancy reduction theory (Dunlosky \& Hertzog, 1998; Thiede \& Dunlosky, 1999) states that participants will allocate study time to items thought to have the largest discrepancy between the perceived current learning state and the desired learning state. This has typically been tested by examining variables that influence recall (such as the associative strength of word pairs) and determining, on the basis of differences in perceived difficulty and actual learning, how judgments are made. The present findings show that perceptual information guides (and can also misguide) these judgments. Thus, the discrepancy reduction model must also address how the physical properties of the stimulus can contribute to discrepancies between one's perceived current and desired learning states. We note that recent theories of the relation between monitoring and control (e.g., Metcalfe \& Kornell, 2005) suggest that variables other than the perceived discrepancy between the current and desired learning state can influence study choices. For example, participants will study easier items more than difficult items when the total amount of study time is limited (Son \& Metcalfe,
2000). Future work should examine how manipulations of perceptual information interact with such variables and contribute to participants' evaluations of the rate at which they are learning (Metcalfe \& Kornell, 2005).

The observation that perceptual information informs JOLs, as well as control of study, also has implications of applied importance. For example, if students integrate easily available perceptual cues (e.g., size, loudness) as a means of assessing learning, they may exhibit overconfidence when such perceptual cues have no bearing on their mastery of material. Moreover, the data reported here for restudy choices, indicating that restudy was strongly influenced by perceptual information, suggest that study time allocation may not be optimal when perceptual cues are not diagnostic of learning. Thus, it is critical that students know that, in some cases, perceptual information is entirely unrelated to learning and develop study strategies that take these factors into account.

Overall, the present study provides crucial evidence linking the perceptual qualities of stimuli to predictions of memory performance and extends theories regarding the types of cues that inform metacognitive judgments (cf. Koriat, 1997). These experiments illustrate important cases in which metacognition is strongly guided by the perceptual qualities of a stimulus, even when memory is not influenced by these factors. In addition, the present study is the first to show a relation between the perceptual qualities of stimuli and control processes. Such data suggest that higher order cognitive processes, such as those putatively involved in metacognition, are influenced by bottom-up perceptual information.

\section{AUTHOR NOTE}

We thank John Dunlosky for helpful comments on an earlier version of this article and Jeffrey Boman, Aaron Dobson, Jessica Jensen, and Haley Smith for assistance with data collection. Please address all correspondence to M. G. Rhodes, Department of Psychology, Colorado State University, Fort Collins, CO 80523-1876 (e-mail: matthew .rhodes@colostate.edu).

\section{REFERENCES}

Begg, I., Duft, S., Lalonde, P., Melnick, R., \& Sanvito, J. (1989). Memory predictions are based on ease of processing. Journal of Memory \& Language, $\mathbf{2 8}, 610-632$.

Benjamin, A. S., Bjork, R. A., \& Schwartz, B. L. (1998). The mismeasure of memory: When retrieval fluency is misleading as a metamnemonic index. Journal of Experimental Psychology: General, 127, $55-68$.

Busey, T. A., Tunnicliff, J., Loftus, G. R., \& Loftus, E. F. (2000). Accounts of the confidence-accuracy relation in recognition memory. Psychonomic Bulletin \& Review, 7, 26-48.

Castel, A. D., McCabe, D. P., \& Roediger, H. L., III (2007). Illusions of competence and overestimation of associative memory for identical items: Evidence from judgments of learning. Psychonomic Bulletin \& Review, 14, 107-111.

Dunlosky, J., \& Hertzog, C. (1998). Training programs to improve learning in later adulthood: Helping older adults educate themselves. In D. J. Hacker, J. Dunlosky, \& A. C. Graesser (Eds.), Metacognition in educational theory and practice (pp. 249-275). Mahwah, NJ: Erlbaum.

Dunlosky, J., \& ThIEDE, K. W. (2004). Causes and constraints of the shift-to-easier-materials effect in the control of study. Memory \& Cognition, 32, 779-788.

Hertzog, C., Dunlosky, J., Robinson, A. E., \& Kidder, D. P. (2003). 
Encoding fluency is a cue used for judgments about learning. Journal of Experimental Psychology: Learning, Memory, \& Cognition, 29, 22-34.

JACOBY, L. L., \& DaLlas, M. (1981). On the relationship between autobiographical memory and perceptual learning. Journal of Experimental Psychology: General, 110, 306-340.

Jacoby, L. L., Kelley, C. M., \& Dywan, J. (1989). Memory attributions. In H. L. Roediger III \& F. I. M. Craik (Eds.), Varieties of memory and consciousness: Essays in honour of Endel Tulving (pp. 391-422). Hillsdale, NJ: Erlbaum.

KelLey, C. M., \& Rhodes, M. G. (2002). Making sense and nonsense of experience: Attributions in memory and judgment. In B. H. Ross (Ed.), The psychology of learning and motivation: Advances in research and theory (Vol. 41, pp. 293-320). San Diego: Academic Press.

Korenman, L. M., \& PeynircioĞLu, Z. F. (2004). The role of familiarity in episodic memory and metamemory for music. Journal of Experimental Psychology: Learning, Memory, \& Cognition, 30, 917-922.

KoRIAT, A. (1997). Monitoring one's own knowledge during study: A cue-utilization approach to judgments of learning. Journal of Experimental Psychology: General, 126, 349-370.

Koriat, A. (2007). Metacognition and consciousness. In P. D. Zelazo, M. Moscovitch, \& E. Thompson (Eds.), The Cambridge handbook of consciousness (pp. 289-325). New York: Cambridge University Press.

KoRIAT, A. (2008). Easy comes, easy goes? The link between learning and remembering and its exploitation in metacognition. Memory \& Cognition, 36, 416-428.

KORIAT, A., \& BJORK, R. A. (2005). Illusions of competence in monitoring one's knowledge during study. Journal of Experimental Psychology: Learning, Memory, \& Cognition, 31, 187-194.

Koriat, A., Ma'ayan, H., \& Nussinson, R. (2006). The intricate relationships between monitoring and control in metacognition: Lessons for the cause-and-effect relation between subjective experience and behavior. Journal of Experimental Psychology: General, 135, 36-69.

KUČERA, H., \& FRANCIS, W. N. (1967). Computational analysis of presentday American English. Providence, RI: Brown University Press.

Mazzoni, G., \& Nelson, T. O. (1995). Judgments of learning are affected by the kind of encoding in ways that cannot be attributed to the level of recall. Journal of Experimental Psychology: Learning, Memory, \& Cognition, 21, 1263-1274.
Metcalfe, J. (2000). Metamemory: Theory and data. In E. Tulving \& F. I. M. Craik (Eds.), The Oxford handbook of memory (pp. 197-211). New York: Oxford University Press.

Metcalfe, J., \& Finn, B. (2008). Evidence that judgments of learning are causally related to study choice. Psychonomic Bulletin \& Review, 15, 174-179.

Metcalfe, J., \& Kornell, N. (2005). A region of proximal learning model of study time allocation. Journal of Memory \& Language, 52, 463-477.

NeLson, T. O. (1984). A comparison of current measures of the accuracy of feeling-of-knowing predictions. Psychological Bulletin, 95, 109-133.

Nelson, T. O. (1996). Consciousness and metacognition. American Psychologist, 51, 102-116.

Oppenheimer, D. M. (2008). The secret life of fluency. Trends in Cognitive Sciences, 12, 237-241.

Rhodes, M. G., \& Castel, A. D. (2008). Memory predictions are influenced by perceptual information: Evidence for metacognitive illusions. Journal of Experimental Psychology: General, 137, 615-625.

Rhodes, M. G., \& Kelley, C. M. (2003). The ring of familiarity: False familiarity due to rhyming primes in item and associative recognition. Journal of Memory \& Language, 48, 581-595.

SCHWARZ, N. (2004). Metacognitive experiences in consumer judgment and decision making. Journal of Consumer Psychology, 14, 332-348.

Son, L. K., \& Metcalfe, J. (2000). Metacognitive and control strategies in study-time allocation. Journal of Experimental Psychology: Learning, Memory, \& Cognition, 26, 204-221.

ThieDE, K. W., \& DunLosKY, J. (1999). Toward a general model of selfregulated study: An analysis of selection of items for study and selfpaced study time. Journal of Experimental Psychology: Learning, Memory, \& Cognition, 25, 1024-1037.

WhitTlesea, B. W., JaCOBY, L. L., \& GiRARD, K. (1990). Illusions of immediate memory: Evidence of an attributional basis for feelings of familiarity and perceptual quality. Journal of Memory \& Language, 29, 716-732.

(Manuscript received December 3, 2008; revision accepted for publication February 12, 2009.) 